\title{
An Empirical Analysis of the income Gap between Industries in Hebei Province
}

\author{
WANG Mengnan \\ School of Economics and Management, Beijing Jiaotong University, China \\ 15120533@bjtu.edu.cn
}

\begin{abstract}
Keywords: Income gap between industries, Theil Index, Cointegration model, Error correction model.
\end{abstract}

\begin{abstract}
First of all, from the perspective of the descriptive statistics, the study is based on relevant statistical data and evaluates the income gap between industries in Hebei province in terms of extremum difference, extremum ratio, Theil index and so on. Then, the relationship between the income gap between industries and economic growth in Hebei province is analyzed. Finally, we can get the conclusion that the effect of income gap between industries to economic growth is negative no matter in the long term or the short term.
\end{abstract}

\section{Introduction}

Since the reform and opening up, especially since the twenty-first century, the economy of Hebei province has been growing at a relatively fast pace, and great achievements have been made in economic construction and social construction, people's income level and the quality of life improved rapidly as well. However, it also triggered a series of problems, such as, unreasonable income distribution system, oversight of government management and lax supervision, which hinders the economic development, and expands the income gap between industries. Moreover, when the situation is serious, it may even lead to the sharpening contradictions between the social stratum, the resentment of the masses, and many other problems. As we all know, income gap between industries refers to the income gap between workers in different industries. The 18th CPC National Congress first put forward "on building moderately prosperous society". In a word, narrowing the income gap between the industry and raising the income level of the low income people, will be conducive to the realization of a comprehensive well-off. Therefore, it is significant to find out the trend of the income gap between industries and reasons for this trend, at the same time, whether there is a correlation between income gap between industries and economic growth is also of far-reaching significance.

\section{Literature Review}

The income gap between the industry is very common in our daily life and has a deep impact on our lives. Therefore, scholars in various countries have conducted in-depth research and obtained various conclusions. Alan B Krueger (1998) uses cross-sectional and longitudinal data to examine differences in pay for equally-skilled workers in different ind ustries and finds out that workers in high-wage indus tries receive noncompetitive rents[1]. With the help of fuzzy maths and AHP model, Yao Fang(2004) uncovered the relative wage level among three different trades of industries[2]. Fu Shuai(2008) thinks that divergence of industry labor productivity are the main factors which make the difference of industry income and influence the industry income actively[3]. Yu Liangchun(2014) uses the Oaxaca-Blinder decomposition method to analyze the income gap between competitive industries and monopoly industries[4]. Li Jun(2015) gets the main conclusions:industry monopoly has become an important factor which impacts the industry income gap in China and differences in the level of human capital of industries exert a more significant impact on the industry income[5]. 


\section{Descriptive Statistical Analysis of income Gap between Industries in Hebei Province}

The trend of income Gap between Industries. In recent years, the economy of Hebei province develops rapidly, followed by the income gap between industries. In this paper, by studying the data of different industries in Hebei Province, the income gap is obtained, as shown in Figure 1.

As can be seen from Figure 1, since 1995, in addition to 2012, the maximum wage curve, has been growing, from slow growth to rapid growth. But at the same time, although the minimum wage curve has been an upward trend, the growth rate is slow, even far lower than the maximum wage growth. Therefore, the difference between the two wages also leads to the rapid growth of the extreme difference, and, the income gap increased significantly.

Next we analyze the extreme ratio, from 1995 to 2001, the extremum ratio of income in Hebei province sometimes reduces or decreases. But it is always less than 3, that is to say, it is reasonable, because the smaller the extreme ratio, the smaller the income gap between industries. However, the extremum ratio has sharply increased since 2002, reaching the peak 5.03 in 2013. Although some years it is in a downward trend, the values remain above 4 , showing that in recent years, the income gap exceeds the reasonable range and needs to take more effective measures.

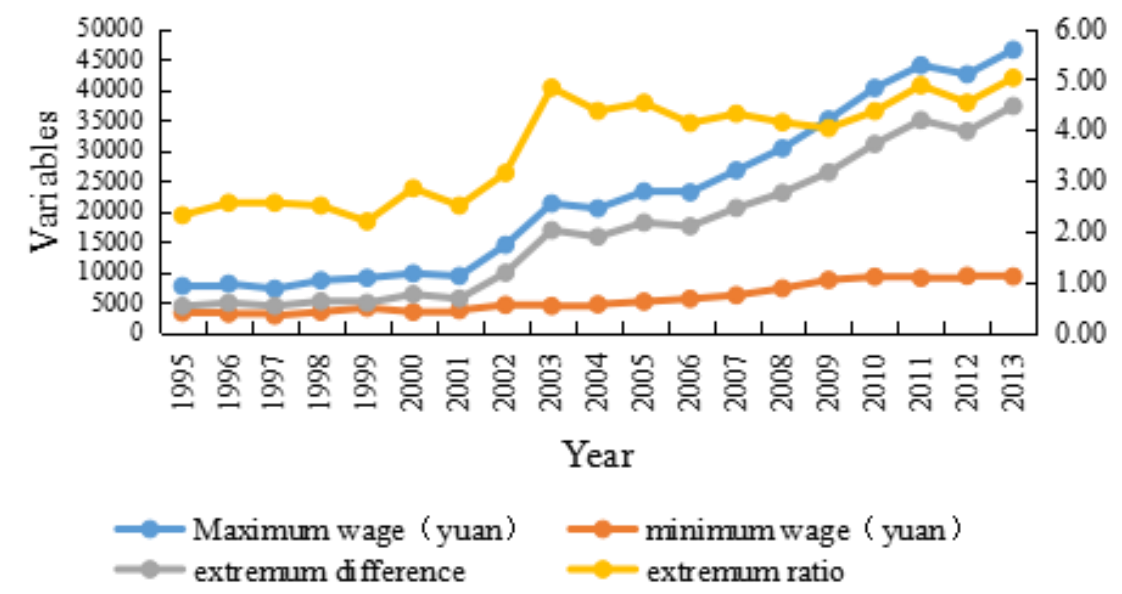

Fig. 1 The related data figure

It is far from enough to only discuss the above data, so the variation coefficient and Theil index are introduced. Form the figure 2, we can see that the coefficient of variation shows a fluctuating state, which appeared two peaks in 2003 and 2011, respectively, 0.3907 and 0.4157 . What's more, the variation range of the variation coefficient is not large, but it is still in a non normal state, which is consistent with the analysis of the extreme difference and the maximum ratio of 2003-2010.

Moreover, Theil index is similar with the variation coefficient. There are 16 industries before 2003, while it has increased to 19 since 2003. Therefore, we analyze the Theil index into two parts. The Theil index shows an upward trend before 2002, while, it has declined overall since 2003.

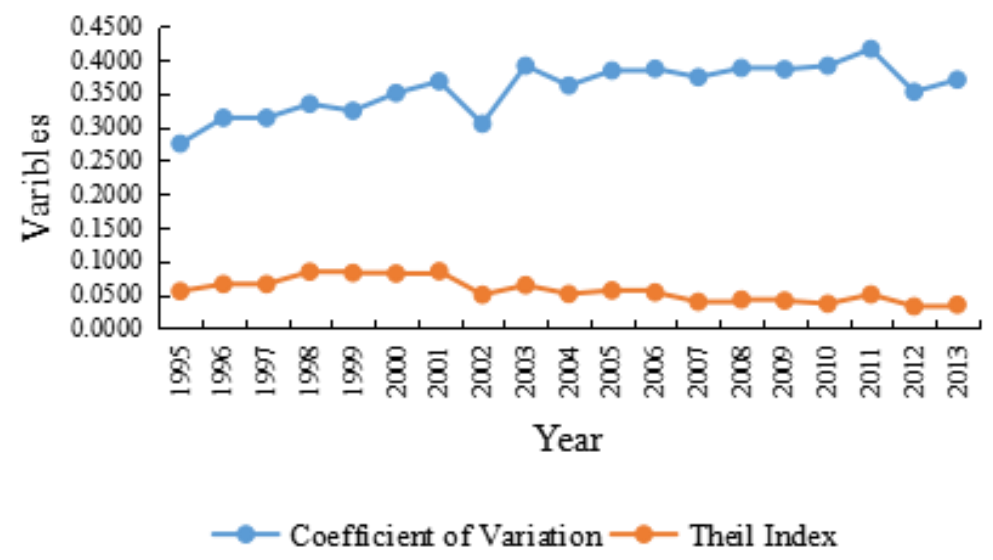

Fig. 2 The coefficient of variation and Theil Index 
Characteristics of the change of income Gap between Industries.In recent years, the income of Heibei Province increases rapidly. For example, per capita income in 2013 is 2.2 times as much as that in 2005. In order to understand the characteristics of the income gap between industries, top three and ranked three industries from 2008 to 2013 are used for research.

Generally speaking, the state monopoly industry or high-tech industry has a high income, and they usually have the following characteristics: first, the industry needs a relatively high level of science and technology, for example, people who engaged in geological prospecting industry not only needs a high degree of education, but also requires strong professional skills. Second, these industries are highly innovative high-tech industries, such as computer services and software industry. These industries need innovative capabilities, faster knowledge update. Third, the industries with a monopoly power have high wage, such as electricity and the financial sector, the former has a state monopoly, while the latter has a capital or industry monopoly. However, the industry which has a lower income of the industry is generally catering industry, agriculture, wholesale and retail industry and other traditional industries. As we all know, they do not need too many professional skills, and do not have a competitive advantage. In addition, the social service industry has not received enough attention, so wage is low.

\section{An Empirical Analysis of the income Gap and Economic Growth in Hebei Province}

Data Selection and Processing. In this part, with the help of EViews5.0 software, two variables are selected. Theil Index(TZ) represents the income gap between industries in Hebei Province, while per capita GDP represents economic growth. First, per capita GDP increased in the form of index. In order to reduce the amount of data, at the same time, to ease the heteroscedasticity of the data, the per capita GDP data were processed by logarithm, and, the single log model between the income gap between industries and the per capita GDP in Hebei Province is established, that is, the model of TZ and LNPGDP.

Empirical Analysis.This section consists of three parts, including unit root test, Cointegration test and error correction model.

The first step we need to do is unit root test.By means of ADF method, the unit root test carries out, and the inspection result is shown in table1. It can be seen from the test results that the ADF test statistics of all the variables, in the $95 \%$ confidence, are greater than the critical value, that is, there is a unit root, and it is a non-stationary time series. However, after the first order difference, all the ADF test statistics, under the confidence level of $95 \%$ are significantly less than the critical value, that is to say, it is a stationary series. Therefore, LNPGDP and TZ variables are the same order single integration process, that is, I (1) process.

Table1 Unit root test for each variable

\begin{tabular}{clccc}
\hline Variables & ADF & 5\% significant level & P & stationarity \\
\hline$T Z$ & -3.5464 & -3.7912 & 0.0734 & No \\
$\Delta T Z$ & -6.2459 & -3.7332 & 0.0007 & Yes \\
$L N P G D P$ & 0.3144 & -3.0522 & 0.9717 & No \\
$\Delta L N P G D P$ & -4.5068 & -3.7597 & 0.0145 & Yes \\
\hline
\end{tabular}

Cointegration test is also very important. The two variables are all first-order single integration processes, so the Cointegration analysis can be done. According to the purpose of the study, the LNPGDP is used as the explanatory variable, while TZ will be used as the explanatory variable. The results show that under $95 \%$ confidence, the residual sequence does not exist in the unit root, so, LNPGDP and TZ have a Cointegration relationship. That is, the income gap between industries and the per capita GDP have a long-term equilibrium relationship. Therefore, we can get the Cointegration equation.

$$
\begin{array}{ccc}
T Z= & 0.8260- & 0.0896 L N P G D P \\
\mathrm{t} & 5.2015 & -4.8401
\end{array}
$$




$$
\begin{aligned}
& \begin{array}{lll}
P & 0.0001 & 0.0002
\end{array} \\
& R^{2}=0.5942 \bar{R}^{2}=0.5688 \quad D . W .=1.6092 F=23.4269
\end{aligned}
$$

It can be known that the equation has a good effect. The overall linear relationship of the equation can be established, and the variables and constants of the equations are verified under the $95 \%$ confidence level, so the Cointegration model can be used. In the long term, changes in per capita GDP in Hebei province will cause the income gap between the industry in the opposite direction change ratio. When the per capita GDP in Hebei province increases by $1 \%$, the income gap between the industry will fall more than $0.0896 \%$.

Finally, what we need to do is to build the error correction model. It has proved that the income gap between industries in Hebei province has a long-term Cointegration relationship with the per capita GDP of Hebei Province, so it can be established ECM. The following model can be obtained by Eviews software.

$$
\begin{aligned}
& \Delta T Z=-0.0981 \Delta L N P G D P-0.0905 e c m(-1) \\
& R^{2}=0.4222 \bar{R}^{2}=0.3837 \text { D.W. }=1.9959
\end{aligned}
$$

The effect of the equation is better. The coefficient of ECM is negative, which is with the reverse correction mechanism and shows that there is a trend of the equilibrium no matter in long term or short term.In the short term, the change in per capita GDP will lead to a reverse change in the income gap. Moreover, whether it is in the long term or in the short term, economic growth will lead to narrow the income gap between industries, but the degree of narrowing is not large. In a word, the economic growth of Hebei province has a very little inhibitory impact on the income gap between industries in Hebei province.

\section{Summary}

This paper intends to study the income gap between industries in Hebei Province, including the changes of the income gap and the empirical study on the relationship between the income gap and economic growth. With the help of descriptive and empirical analysis, we can draw the following conclusions.

In Hebei, traditional industries such as agriculture generally have low income. Moreover, social service industry has not been widely concerned, so the income is low. However, industry which has monopoly power as well as high-tech industries generally have a high income.

By establishing econometric model, we know that the economic growth of Hebei province is one of the reasons for the income gap between the industries, and the two of them shows a reverse change relationship.

\section{References}

[1] Alan B Krueger, Lawrence H Summers, Efficiency Wages and the Inter-industry Wage Structure, Econometrica, vol 56(1998), p259-293.

[2] YAO Fang, YAO Pin, SUN Lin-yan, A Study of Reasonable Inter-trade Income Distribution in China, Journal of ShanXi Finance and Economics University, vol 26(2004), p48-50.

[3] FU Shuai, GONG Zhi-min, Analysis of the Cause and Economic Growth Affect of Chinese Income Gap between Industries, Journal of Shanxi Finance and Economics University, $\operatorname{vol30(2008),~p22-27.~}$

[4] YU Liang-chun, WANG Mei-chen, Industry Monopoly and Empirical Analysis of Its Impact on the Income Distribution Gap,Research on Economics and Management, vol 7(2014), p23-33.

[5] LI Jun, SONG Shan-yan, An Analysis on the Influencing Factors of China's Inter-industry Income Gap, Journal of Hunan University (Social Sciences), vol 29(2015), p90-94. 